\title{
Developmental and behavioral outcomes of uncomplicated monochorionic diamniotic twins born in the third trimester
}

This article was published in the following Dove Press journal:

Neuropsychiatric Disease and Treatment

19 May 2017

Number of times this article has been viewed

\section{Amy Sierakowski' \\ Valsamma Eapen ${ }^{2,3}$ \\ Rudi Črnčec ${ }^{2,3}$ \\ John Smoleniec ${ }^{4,5}$}

'University of New South Wales, ${ }^{2}$ School of Psychiatry, University of New South Wales, ${ }^{3}$ Academic Unit of Infant, Child and Adolescent Psychiatry, Ingham Institute, Liverpool Hospital, South Western Sydney Local Health District, ${ }^{4}$ Division of Women's and Children's Health, University of New South Wales, Sydney, ${ }^{5}$ Department of MaternalFetal Medicine, Liverpool Hospital, Liverpool, NSW, Australia
Correspondence: Valsamma Eapen Academic Unit of Infant, Child and Adolescent Psychiatry, Ingham Institute, Liverpool Hospital, South Western Sydney Local Health District, Mental Health Centre (Level I: ICAMHS), Locked Bag 7I03, Liverpool BC, NSW I87I, Australia Email v.eapen@unsw.edu.au
Background: Relatively little is known about the neurodevelopmental and behavioral outcomes of monochorionic diamniotic (MCDA) twin pregnancies where there are no antenatal complications peculiar to monochorionicity or prematurity.

Methods: Twenty-two MCDA twins (44 children) with an average age of 4.3 years, and with no antenatal complications detected by 28 weeks of gestation, were recruited from a feto-maternal unit database. Parents completed a battery of neurodevelopmental and behavioral assessment questionnaires.

Results: Eighteen children (41\%) were identified as having developmental or behavioral concerns, predominantly of mild severity, which in turn were associated with a lower birth weight of medium effect size (Cohen's $d=0.59$ ).

Conclusion: MCDA twins delivered in the third trimester with no antenatal monochorionic complications in the first two trimesters appear to be at risk for subtle neurodevelopmental difficulties, associated with a lower birth weight. Ongoing developmental surveillance of these children during preschool-age is indicated for early identification and intervention.

Keywords: monochorionic, diamniotic, twin, neurodevelopment, behavior, long-term outcome

\section{Introduction}

All multiple pregnancies are at an increased risk of antepartum complications, relative to singletons. In monochorionic (MC) multiples, the perinatal morbidity and mortality risk is significantly higher than dichorionic (DC) twins, which are the commonest type of twins. ${ }^{1-3}$

Approximately one in 80 births in Australia is twins, and of these, around $30 \%$ are monozygotic (identical). MC diamniotic (MCDA) twins are identical twins who share a placenta but not an amniotic sac, with this architecture arising in around two-thirds of monozygotic twins, ${ }^{1,4,5}$ or around one in 400 of all pregnancies.

MCDA pregnancies are associated with three to six times increased risk of complications compared to DC twins, where each fetus has its own placenta. ${ }^{6-9}$ Due to the presence of placental vascular anastomoses, various complications can occur including twin-twin transfusion syndrome (TTTS), twin anemia polycythemia sequence (TAPS), twin reversed arterial perfusion (TRAP), and selective intrauterine growth restriction (sIUGR). In addition, severe discordant congenital anomalies occur more frequently in MCDA pregnancies and are associated with an increased risk of morbidity and mortality. ${ }^{10}$ In the case of spontaneous intrauterine demise of one fetus, its co-twin may subsequently die (15\%) or suffer from severe cerebral injury (34\%) due to acute 
exsanguinations into the circulation of the demised twin through the placental vascular anastomoses. ${ }^{11}$

Although long-term outcome has been studied extensively in cohorts of children delivered following specific MCDA complications, including TTTS ${ }^{12}$ and co-twin death survivors, ${ }^{13}$ only a few studies have investigated the longterm outcomes in $\mathrm{MC}$ and $\mathrm{DC}$ twin cohorts in general. ${ }^{14-16}$

In a study comparing the neurological outcomes of MCDA and DC diamniotic (DCDA) twins, Adegbite et a ${ }^{15}$ documented the rates of neuromorbidity to be $23 \%$ and $4 \%$, respectively. Advances in the treatment of TTTS have decreased its influence on these outcomes; however, the neuromorbidity rates of more recent studies by Acosta-Rojas et $\mathrm{al}^{6}$ (3\% complicated, $0.5 \%$ uncomplicated) and Ortibus et a $\mathrm{l}^{17}$ (10\% complicated, $7 \%$ uncomplicated) continue to provide a wide range of risk estimates.

Hack et a $1{ }^{14}$ compared neurodevelopmental outcomes in 140 MCDA and 142 DCDA children recruited across nine sites at age 22 months, using the Health Status Classification System Preschool children (HSCS-PS) questionnaire completed by parents, the findings of which were in concordance with those of the Griffiths Mental Development Scales. The authors reported that the majority of 2-year-old twins had normal developmental status, and that there were no significant differences between $\mathrm{MC}$ and $\mathrm{DC}$ twins, apart from a slight delay in hearing and language development in MC twins. Birth weight discordancy did not appear to influence long-term outcome, although there was a trend toward lower Griffith Developmental Quotient (DQ) scores in the smaller twin than in its larger co-twin. There was, however, a significant difference in development between boys and girls, whereby boys had lower DQ scores and the proportion of mildly delayed development was higher amongst male infants. Moreover, infants born before 32 weeks of gestation and/or with a birth weight $<1,500 \mathrm{~g}$ had significantly lower DQ scores than infants born after 32 weeks and/or with a birth weight of $\geq 1,500 \mathrm{~g}$. The study showed that across both the MC and DC groups, the largest proportion of identified developmental concerns on the Griffith scales was within the locomotor domain (ie, $26.5 \%$ of the MC group). The authors noted that follow-up at an older child age would be preferable as difficulties relating to neurological handicaps and intellectual disability may only become evident at that time.

Nonetheless, differences in selection/exclusion criteria, criteria for neurodevelopmental delay, and typically small study cohorts make comparison of the available studies difficult. It is also difficult to ascertain factors influencing uncomplicated MCDA twins specifically, given the mixed cohorts which have included the full range of complications including TTTS, co-twin death, and premature birth. Critically, studies have tended to focus on mortality and core neurodevelopmental status, while not exploring the impacts upon socio-emotional and behavioral development.

Thus, there do not appear to be any studies available where the effects of uncomplicated MCDA pregnancy on long-term neurodevelopmental outcome are examined. These are important questions because such pregnancies form the majority of cases, and the structural challenges of shared placental anatomy do conceivably place the fetus at risk for mild neurodevelopmental difficulties as well as socio-emotional and behavioral challenges, which may be evident only later in the child's life. Further, the literature suggests that MCDA pregnancies that appear uncomplicated using standard screening procedures may indeed carry significant undetected complications, sometimes leading to fetal death. ${ }^{18}$

The aim of the study was to examine longer-term neurodevelopmental outcomes in a cohort of antenatally uncomplicated MCDA twins delivered in the third trimester.

\section{Methods}

The study had ethical approval from the Human Research Ethics Committees of the South Western Sydney Local Health District and University of New South Wales.

\section{Procedure}

The study was undertaken at the feto-maternal unit (FMU) at Liverpool Hospital in Sydney. Liverpool Hospital is a tertiary referral center in the South Western Sydney Local Health District, which covers a total of seven local government areas and an estimated population of $820,000 .{ }^{19}$ The FMU provides a tertiary prenatal scanning, testing, and counseling service for approximately 3,500 pregnancies out of a total obstetric population of 12,000 per year as a subunit of the Division of Women's and Children's Health at the University of New South Wales.

The study used both retrospective and prospective methodology. Retrospective data were extracted from the existing FMU database in the form of an initial patient list, by selecting for MCDA pregnancies that were uncomplicated and undelivered before 28 weeks between the 1st of January 2007 and 31st of December 2009. Prospective data were collected in the form of three parent-completed questionnaires that were sent and received by mail.

There were 97 cases of MCDA twins with a gestational age $>28$ weeks during the study period between 2007 and 
2009. Twenty-seven cases were deemed unsuitable for the study due to complicated status and/or wrongful inclusion by the data extraction process, and were therefore excluded. Of the remaining 70 cases, eight were listed as requiring an interpreter and were excluded from the final list due to the unavailability of an interpreter to the study due to resourcing, leaving 62 eligible cases. A further 16 of these cases were uncontactable, leaving a final pool of 46 eligible cases.

Consent to participate in the study was obtained via an initial phone call in 44 cases, with two patients declining to participate. Study packs, which included a study information and consent form for patients to sign, were sent to these 44, and follow-up phone calls were made if packs were not returned within 3 weeks. Twenty-two packs were ultimately returned within the allotted time period for data collection of 2 months, providing a response rate of $50 \%$ (22 of 44).

Information about the pregnancy and birth details of the child were obtained from the FMU internal database and New South Wales Electronic Medical Records. These included gestational age at birth, birth weight and estimated fetal weight and their percentiles, mode of delivery, Apgar scores, and ultrasound Doppler studies.

Chorionicity was determined by ultrasound in accordance with accepted criteria. ${ }^{4,5}$ All pregnancies for which this was not conclusive were treated as MC until chorionicity was confirmed antenatally by placental histology. The term "uncomplicated" was used to define those pregnancies unaffected by MC-specific conditions and identifiable discordant growth patterns up to 28-week gestational age. Pregnancies complicated by major congenital malformations, aneuploidy, and the intrauterine demise of a co-twin were also excluded. The MC-specific conditions, TTTS, TAPS, and TRAP were identified sonographically. ${ }^{20-22}$ Comparison with an uncomplicated DC control group was not possible as only MC twins are offered routine surveillance every 2 weeks until delivery in the FMU.

Participant study packs comprised the Child Behaviour Checklist (CBCL), ${ }^{23}$ Child Development Chart (CDC), ${ }^{24}$ and a parent questionnaire.

The $\mathrm{CBCL}^{23}$ has strong psychometric properties and was scored using the associated Achenbach System of Empirically Based Assessment scoring profile. ${ }^{25} \mathrm{CBCL}$ results were converted into norm-referenced percentiles for the six behavior domains: anxious/depressed, withdrawn, sleep problems, somatic problems, aggressive behavior, and destructive behavior. Percentile scores were categorized as normal ( $<95$ th percentile), borderline (95th-98th percentile), or clinical ( $>98$ th percentile). These behavior domains were collapsed into composite internalizing (anxious/depressed and withdrawn), externalizing (aggressive and destructive behavior), and total domain score categories, which were reported as a norm-referenced " $T$ " score out of 100 , with categories of normal $(T<60)$, borderline $(T=60-63)$, and clinical $(T>63)$.

The $\mathrm{CDC}^{24}$ was scored by calculating the DQ (that is, $\left.\left(\frac{\text { Developmental age }}{\text { Chronological age }}\right) \times 100\right)$ of the child in the domains of social, self-help, gross motor, fine motor, and language, as well as an overall DQ, which was calculated as the average of the five domain scores. Quotients were classified as normal $(>85)$, borderline (85-70), and clinical $(<70) .{ }^{26}$ The CDC chart did not test beyond 58 months, so parents with children aged $>58$ months were asked to complete the chart from their memory of the child at that age; hence, chronological age used in this scenario was 58 months. There is a long history of research supporting the accuracy of parent self-report of child development when using structured inventories. ${ }^{27,28}$ For example, in their 2013 review, Bedford et al reported that

Measures completed by parents have been shown to be as accurate as those administered by professionals in identifying children with developmental problems (p. 59). ${ }^{29}$

The parent questionnaire was constructed for the purposes of the study to obtain specific information regarding demographics of the child, diagnosed developmental issues, and his/her family background.

\section{Statistical analyses}

Data were analyzed using SPSS software. In light of the small sample size recruited for this study, a predominantly descriptive approach was taken to the data analysis. Independent $t$-tests were used in a broad comparison of all developmental and behavioral problems with birth weight and gestational age. The Cohen's $d$ metric was used to calculate effect sizes and was calculated by dividing the mean difference between groups by the pooled standard deviation (SD). It is widely accepted that Cohen's $d$ values of $0.2-0.49$ denote small-sized effects, 0.5-0.79 denote medium-sized effects, and $>0.8$ denote large effect sizes.

\section{Results}

Of the 22 pairs of twins included in the study, the mean age was 4.3 years $(\mathrm{SD}=0.65)$. The cohort was split evenly by sex, with 11 male and 11 female twin pairs. Additional baseline family data of these pairs are summarized in Table 1. 


\section{Pregnancy outcome}

All 22 pregnancies resulted in live births. Conception was assisted in three pregnancies, by either in vitro fertilization (IVF) $(n=2)$ or intracytoplasmic sperm injection $(n=1)$, and was spontaneous in the remaining 19 pregnancies. Twenty-four of the deliveries were by elective cesarean section (54.6\%). In two cases, an emergency cesarean section was performed following the vaginal birth of the first twin due to birth complications (placental abruption and uncorrectable malpresentation). Mean gestational age was 35 weeks and 5 days, with a range from 29 to 38 weeks. The distribution of gestational ages was relatively normal with no evidence of bimodality: only two cases were born at $<32$ weeks ( 29 weeks 3 days in both the cases). Mean birth weight was 2,306 g, and three sets of twins presented with significant birth weight discordances of $26.7 \%, 27 \%$, and $33.1 \%$. As these three sets of twins were not identified using the antenatal screening methodology employed in the study, they were retained in the sample. Average birth weight discordancy within the cohort was $13 \%$. The mean maternal age was 32.2 years with a range of $20-40$ years. Preeclampsia was diagnosed in one primiparous pregnancy,

Table I Family data

\begin{tabular}{ll}
\hline Characteristics & $\mathbf{n ~ ( \% )}$ \\
\hline Number of children in the family & \\
2 & $12(27.3)$ \\
3 & $22(50)$ \\
4 & $6(13.6)$ \\
5 & $4(9.1)$ \\
Total & $44(100)$ \\
Birth order & \\
I & $9(20.5)$ \\
2 & $18(40.9)$ \\
3 & $13(29.5)$ \\
4 & $3(6.8)$ \\
5 & $1(2.3)$ \\
Total & $44(100)$ \\
Family make-up & \\
Living with both parents & $40(90.9)$ \\
Living with one parent & $4(9.1)$ \\
Total & $44(100)$ \\
Family income (AUD) & \\
$<25,000$ & $4(9.1)$ \\
$25,00 I-40,000$ & $2(4.5)$ \\
$55,00 I-70,000$ & $4(9.1)$ \\
$70,00 I-85,000$ & $12(27.3)$ \\
$85,00 I-100,000$ & $8(18.2)$ \\
I00,00I-II5,000 & $6(13.6)$ \\
$>$ II 5,000 & $4(9.1)$ \\
Did not wish to answer & $4(9.1)$ \\
Total & $44(100)$ \\
\hline A6brevition AUD, Austal &
\end{tabular}

Abbreviation: AUD, Australian dollar. resulting in an overall prevalence of $4.5 \%$ which is lower than the recorded figures for nulliparous (26.7\%) and primi-/ multiparous (17.1\%) MC pregnancies. ${ }^{30}$ Full pregnancy and birth details can be found in Table 2 .

\section{Developmental and behavioral outcomes}

Developmental and behavioral data in the form of the parent survey and CBCL were received for all the children. Of the conditions specifically screened for in the parent survey, cases of speech delay requiring speech pathology $(n=6$, $14 \%$ - children $8,9,10,11,17$, and 18 in Table 3), anxiety $(\mathrm{n}=2,4.5 \%$ - children 6 and 7 in Table 3$)$, and cerebral palsy (CP) $(\mathrm{n}=1,2.3 \%$ - child 12 in Table 3$)$ were reported. In addition, other medical issues were reported as follows: asthma $(n=3,6.8 \%)$, eczema $(n=3,6.8 \%)$, and vision problems $(n=2$, $4.5 \%)$; however, these were not considered in subsequent analyses. Details of diagnosis, severity, and treatment were not provided by parents.

CBCL results are presented in Table 4 and are organized according to normal, borderline, and clinical categories. The average frequency of normal scores in the six CBCL

Table 2 Pregnancy outcomes for children in the study

\begin{tabular}{|c|c|c|}
\hline Parameters & Per child & Per pregnancy \\
\hline Total number & $44(100)$ & $22(100)$ \\
\hline \multicolumn{3}{|l|}{ Method of conception } \\
\hline Spontaneous & $38(86.4)$ & $19(86.4)$ \\
\hline Assisted & $6(13.6)$ & $3(13.6)$ \\
\hline \multicolumn{3}{|c|}{ Delivery method (at least one birth) } \\
\hline Vaginal & $14(31.8)$ & $8(36.4)$ \\
\hline \multicolumn{3}{|l|}{ Cesarean section } \\
\hline Elective & $24(54.5)$ & $12(54.5)$ \\
\hline Emergency & $6(13.6)$ & $4(18.2)$ \\
\hline \multirow[t]{2}{*}{ Gestational age } & $250(14)$ & \\
\hline & (35 weeks, 5 days) & \\
\hline Birth weight $(g)$ & $2,306.1 \pm 528.3$ & \\
\hline \multicolumn{3}{|l|}{ Birth weight discordancy } \\
\hline$<25 \%$ & $38(86.4)$ & $19(86.4)$ \\
\hline$>25 \%$ & $6(13.6)$ & $3(13.6)$ \\
\hline \multicolumn{3}{|c|}{ Non-MCDA pregnancy complications } \\
\hline Light bleeding, first trimester & $8(18.2)$ & $4(18.2)$ \\
\hline Preeclampsia & $2(4.5)$ & I (4.5) \\
\hline \multicolumn{3}{|l|}{ Maternal factors } \\
\hline Maternal age (years) & $32.18(5.2)$ & \\
\hline \multicolumn{3}{|l|}{ Smoking } \\
\hline Yes & $0(0)$ & $0(0)$ \\
\hline No & $42(95.5)$ & $21(95.5)$ \\
\hline Unanswered & $2(4.5)$ & I (4.5) \\
\hline \multicolumn{3}{|l|}{ Alcohol } \\
\hline Yes & $2(4.5)$ & I (4.5) \\
\hline No & $36(81.8)$ & $18(81.8)$ \\
\hline Unanswered & $6(13.6)$ & $3(13.6)$ \\
\hline
\end{tabular}

Note: Data are presented as $n(\%)$ or mean \pm SD.

Abbreviations: MCDA, monochorionic diamniotic; SD, standard deviation. 
Table 3 Profile of children showing abnormal developmental outcomes

\begin{tabular}{|c|c|c|c|c|c|c|c|c|c|c|}
\hline $\begin{array}{l}\text { Child } \\
\text { ID }\end{array}$ & $\begin{array}{l}\text { Twin } \\
\text { pair }\end{array}$ & Sex & $\begin{array}{l}\text { Age } \\
\text { (years) }\end{array}$ & $\begin{array}{l}\text { Identified } \\
\text { developmental } \\
\text { concern }\end{array}$ & $\begin{array}{l}\text { Gestational } \\
\text { age (weeks) }\end{array}$ & $\begin{array}{l}\text { Method of } \\
\text { conception }\end{array}$ & $\begin{array}{l}\text { Birth } \\
\text { weight } \\
\text { (g) }\end{array}$ & $\begin{array}{l}\text { Birth weight } \\
\text { discordancy }\end{array}$ & $\begin{array}{l}\text { Pregnancy/birth } \\
\text { details }\end{array}$ & $\begin{array}{l}\text { Other } \\
\text { information/ } \\
\text { comments }\end{array}$ \\
\hline I & A & Female & 3.8 & $\begin{array}{l}\text { Wide-ranging } \\
\text { internalizing and } \\
\text { externalizing } \\
\text { problems } \\
\text { Identified borderline } \\
\text { gross motor delay }\end{array}$ & 36 & Spontaneous & 2,670 & $33.2 \%$ & $\begin{array}{l}\text { Preeclampsia. Light } \\
\text { bleeding in the first } \\
\text { trimester }\end{array}$ & $\begin{array}{l}\text { Immature with } \\
\text { play }\end{array}$ \\
\hline 2 & A & Female & 3.8 & $\begin{array}{l}\text { Externalizing } \\
\text { problems } \\
\text { Identified borderline } \\
\text { gross motor delay }\end{array}$ & 36 & Spontaneous & I,785 & $33.2 \%$ & $\begin{array}{l}\text { Preeclampsia. Light } \\
\text { bleeding in the first } \\
\text { trimester }\end{array}$ & $\begin{array}{l}\text { Gets into things } \\
\text { Does not listen } \\
\text { Visual problems }\end{array}$ \\
\hline 3 & B & Female & 3.8 & $\begin{array}{l}\text { Borderline } \\
C B C L \text { scores } \\
\text { for withdrawn } \\
\text { and internalizing } \\
\text { problems }\end{array}$ & 35 & Spontaneous & 2,890 & $14.2 \%$ & Breech presentation & $\begin{array}{l}\text { Negative biopsy } \\
\text { at } 2 \text { years for } \\
\text { lymphoma } \\
\text { Described as shy }\end{array}$ \\
\hline 4 & B & Female & 3.8 & $\begin{array}{l}\text { Borderline CBCL } \\
\text { scores for somatic } \\
\text { problems }\end{array}$ & 35 & Spontaneous & 2,480 & $14.2 \%$ & & $\begin{array}{l}\text { Shy } \\
\text { Clingy to mother } \\
\text { and sister }\end{array}$ \\
\hline 5 & C & Female & 3.8 & $\begin{array}{l}\text { Identified gross } \\
\text { motor DQ of } 79 \\
\text { (borderline) }\end{array}$ & 36 & Spontaneous & $\mathrm{I}, 780$ & $24.7 \%$ & $\begin{array}{l}\text { Breech presentation. } \\
\text { Apgar at I minute: } 9 \\
\text { and at } 5 \text { minutes: } 9\end{array}$ & \\
\hline 6 & $\mathrm{D}$ & Male & 4.3 & $\begin{array}{l}\text { Anxiety } \\
\text { Borderline DQ for } \\
\text { fine motor }\end{array}$ & 34 & Assisted - IVF & $\mathrm{I}, 700$ & $0.6 \%$ & Placenta previa & $\begin{array}{l}\text { Anxiety percentile } \\
\text { high normal - 78th }\end{array}$ \\
\hline 7 & $\mathrm{D}$ & Male & 4.3 & $\begin{array}{l}\text { Anxiety } \\
\text { Borderline DQ for } \\
\text { fine motor }\end{array}$ & 34 & Assisted - IVF & 1,690 & $0.6 \%$ & Placenta previa & $\begin{array}{l}\text { Anxiety percentile } \\
\text { high normal - 69th }\end{array}$ \\
\hline 8 & $\mathrm{E}$ & Male & 5 & Speech pathology & 32 & Spontaneous & 1,660 & $2.5 \%$ & Normal vaginal birth & $\begin{array}{l}\text { Described as shy } \\
\text { Nose bleeds }\end{array}$ \\
\hline 9 & $E$ & Male & 5 & Speech pathology & 32 & Spontaneous & 1,618 & $2.5 \%$ & $\begin{array}{l}\text { Breech presentation. } \\
\text { Apgar at I minute: } \\
5 \text {, at } 5 \text { minutes: } 9\end{array}$ & $\begin{array}{l}\text { Described as shy } \\
\text { Nose bleeds }\end{array}$ \\
\hline 10 & $\mathrm{~F}$ & Male & 5 & Speech pathology & 32 & Spontaneous & $\mathrm{I}, 570$ & $17.2 \%$ & $\begin{array}{l}\text { Cord loose around } \\
\text { neck. Apgar at } \\
\text { I minute: } 7 \text { and at } \\
5 \text { minutes: } 9\end{array}$ & \\
\hline II & $\mathrm{F}$ & Male & 5 & Speech pathology & 32 & Spontaneous & 1,896 & $17.2 \%$ & $\begin{array}{l}\text { Placental abruption - } \\
\text { emergency cesarean } \\
\text { section. Apgar at } \\
\text { I minute: } 6 \text { and at } \\
5 \text { minutes: } 9\end{array}$ & \\
\hline 12 & G & Female & 3.3 & $\begin{array}{l}\text { Cerebral palsy - } \\
\text { mild. Affects right } \\
\text { hand }\end{array}$ & 35 & Assisted - IVF & 2,555 & $22.5 \%$ & $\begin{array}{l}\text { Elective cesarean } \\
\text { section indicated by } \\
\text { previous cesarean } \\
\text { section }\end{array}$ & $\begin{array}{l}\text { Has lisp. Maternal } \\
\text { diabetes mellitus }\end{array}$ \\
\hline 13 & $\mathrm{H}$ & Female & 3.9 & $\begin{array}{l}\text { Borderline score in } \\
C B C L \text { for anxiety }\end{array}$ & 28 & Spontaneous & 2,980 & $1.3 \%$ & Elective cesarean & Eczema, very shy \\
\hline 14 & I & Male & 3.8 & $\begin{array}{l}\text { Borderline CBCL } \\
\text { scores: anxious/ } \\
\text { depressed, } \\
\text { withdrawn, somatic, } \\
\text { and externalizing } \\
\text { problems. }\end{array}$ & 34 & Spontaneous & 2,905 & $19.8 \%$ & $\begin{array}{l}\text { Vaginal delivery } \\
\text { (induced) }\end{array}$ & $\begin{array}{l}\text { Stutters, so } \\
\text { nervous in new } \\
\text { situations }\end{array}$ \\
\hline & & & & $\begin{array}{l}\text { Clinical scores in } \\
\text { internalizing and } \\
\text { total scores }\end{array}$ & & & & & & $\begin{array}{l}\text { No concentration } \\
\text { span, obsessively } \\
\text { routine }\end{array}$ \\
\hline
\end{tabular}


Table 3 (Continued)

\begin{tabular}{|c|c|c|c|c|c|c|c|c|c|c|}
\hline $\begin{array}{l}\text { Child } \\
\text { ID }\end{array}$ & $\begin{array}{l}\text { Twin } \\
\text { pair }\end{array}$ & Sex & $\begin{array}{l}\text { Age } \\
\text { (years) }\end{array}$ & $\begin{array}{l}\text { Identified } \\
\text { developmental } \\
\text { concern }\end{array}$ & $\begin{array}{l}\text { Gestational } \\
\text { age (weeks) }\end{array}$ & $\begin{array}{l}\text { Method of } \\
\text { conception }\end{array}$ & $\begin{array}{l}\text { Birth } \\
\text { weight } \\
\text { (g) }\end{array}$ & $\begin{array}{l}\text { Birth weight } \\
\text { discordancy }\end{array}$ & $\begin{array}{l}\text { Pregnancy/birth } \\
\text { details }\end{array}$ & $\begin{array}{l}\text { Other } \\
\text { information/ } \\
\text { comments }\end{array}$ \\
\hline 15 & J & Male & 4.7 & $\begin{array}{l}\text { Borderline DQ } \\
\text { gross motor }\end{array}$ & 39 & Spontaneous & $\mathrm{I}, 700$ & $15.6 \%$ & $\begin{array}{l}\text { Prolonged second- } \\
\text { stage labor }\end{array}$ & \\
\hline 16 & J & Male & 4.7 & $\begin{array}{l}\text { Borderline DQ } \\
\text { gross motor }\end{array}$ & 39 & Spontaneous & $\mathrm{I}, 435$ & $15.6 \%$ & $\begin{array}{l}\text { Cord tight around } \\
\text { neck. Apgar at } \\
\text { I minute: } 9 \text {, and at } \\
5 \text { minutes: } 9\end{array}$ & \\
\hline 17 & $\mathrm{~K}$ & Male & 5 & Speech pathology & 39 & Spontaneous & 2,590 & $7.7 \%$ & Elective cesarean & \\
\hline 18 & $\mathrm{~K}$ & Male & 5 & Speech pathology & 39 & Spontaneous & 2,390 & $7.7 \%$ & Elective cesarean & \\
\hline
\end{tabular}

Note: Use of the same letters in the twin pair column denotes a twin data set; only one set of data is presented in the case of some twin pairs where one of the twins was developing normally.

Abbreviations: CBCL, Child Behaviour Checklist; IVF, in vitro fertilization; DQ, developmental quotient.

Table 4 Developmental data - Child Behaviour Checklist

\begin{tabular}{|c|c|c|}
\hline Parameters & Per child & Per pregnancy \\
\hline Total number & $44(100)$ & $22(100)$ \\
\hline \multicolumn{3}{|c|}{ Anxious/depressed ${ }^{a}$} \\
\hline Normal & $42(95.5)$ & $20(91.0)$ \\
\hline Borderline & $2(4.5)$ & $2(9.1)$ \\
\hline Clinical & $0(0)$ & $0(0)$ \\
\hline \multicolumn{3}{|l|}{ Withdrawn ${ }^{a}$} \\
\hline Normal & $4 I(93.2)$ & $19(86.3)$ \\
\hline Borderline & $3(6.8)$ & $3(13.6)$ \\
\hline Clinical & $0(0)$ & $0(0)$ \\
\hline \multicolumn{3}{|c|}{ Sleep problems ${ }^{a}$} \\
\hline Normal & $43(97.7)$ & $21(95.5)$ \\
\hline Borderline & I (2.3) & I (4.5) \\
\hline Clinical & $0(0)$ & $0(0)$ \\
\hline \multicolumn{3}{|c|}{ Somatic problems ${ }^{\mathrm{a}}$} \\
\hline Normal & $42(95.5)$ & $20(91.0)$ \\
\hline Borderline & $2(4.5)$ & $2(9.1)$ \\
\hline Clinical & $0(0)$ & $0(0)$ \\
\hline \multicolumn{3}{|c|}{ Aggressive behaviora } \\
\hline Normal & $43(97.7)$ & $21(95.5)$ \\
\hline Borderline & I (2.3) & I (4.5) \\
\hline Clinical & $0(0)$ & $0(0)$ \\
\hline \multicolumn{3}{|c|}{ Destructive behavior ${ }^{a}$} \\
\hline Normal & $42(95.5)$ & $21(95.5)$ \\
\hline Borderline & $2(4.5)$ & I (4.5) \\
\hline Clinical & $0(0)$ & $0(0)$ \\
\hline \multicolumn{3}{|c|}{ Internalizing composite ${ }^{\mathrm{b}}$} \\
\hline Normal & $4 \mid(93.2)$ & $19(86.4)$ \\
\hline Borderline & $2(4.5)$ & $2(9.1)$ \\
\hline Clinical & I (2.3) & I (4.5) \\
\hline \multicolumn{3}{|c|}{ Externalizing composite ${ }^{b}$} \\
\hline Normal & $4 \mathrm{I}(93.2)$ & $20(91.0)$ \\
\hline Borderline & I (2.3) & I (4.5) \\
\hline Clinical & $2(4.5)$ & I (4.5) \\
\hline \multicolumn{3}{|l|}{ Total scores ${ }^{b}$} \\
\hline Normal & $4 \mathrm{I}(93.2)$ & $19(86.4)$ \\
\hline Borderline & I (2.3) & I (4.5) \\
\hline Clinical & $2(4.5)$ & $2(9.1)$ \\
\hline
\end{tabular}

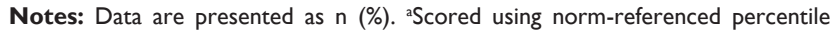
scores where normal is $<95$ th percentile, borderline is 95 th-98th percentile, and clinical is $>98$ th percentile. ${ }^{b} S c o r e d$ using $T$ scores where normal is $T<60$, borderline is $T=60-63$, and clinical is $T>63$. baseline categories per child was $95.9 \%$, indicating a largely problem-free population. Consistent with this, the average $T$ score (SD, range) for the internalizing composite was 43.2 (10.5, 30-67), externalizing composite $41.9(9.0,30-68)$, and overall domain $42.2(10.1,27-70)$.

Borderline scores were identified in all of the nine categories, and clinical scores were identified in three; however, all of the borderline and clinical scores were attributable to only six children. Therefore, six of $44(13.6 \%)$ children were found to have some indication of behavioral/emotional problems by the CBCL. Four of these children comprised two female twin pairs, with the scores of one pair of twins (children 1 and 2 in Table 3) indicating externalizing behavioral difficulties, while those of the other (children 6 and 7 in Table 3) reflected internalizing difficulties. The remaining two children, from separate twin pairs, had vastly different developmental profiles. One (child 13 in Table 3), a female twin with a normal sibling, obtained a borderline score in only one category (anxious/depressed); however, the final child (child 14 in Table 3), a male twin with a normal sibling, received borderline scores in four categories and clinical scores in two. Taken together with the reports of two children experiencing anxiety from parent questionnaire data, the overall rate of behavioral/emotional difficulties was 18\% (eight of 44).

CDC data were received for 36 of 44 children. Results for frequency of scores are summarized in Table 5. Five of $36(13.9 \%)$ children received a borderline score in the gross motor category, while two $(5.6 \%)$ received a borderline score in the fine motor category. Therefore, seven of $36(19.4 \%)$ of the overall cohort showed some indication of motor delay. Of these cases, five children were identified as having borderline scores in the absence of any other developmental concerns as reported by the parents. These cases comprised two twin pairs and a child with a normally scoring sibling (children 6 and 7, 15 and 16, and 5 in Table 3). The two remaining 
Table 5 Developmental data - Child Development Chart

\begin{tabular}{|c|c|c|}
\hline Parameters & Per child & Per pregnancy \\
\hline Total number & $36(100)$ & $18(100)$ \\
\hline \multicolumn{3}{|l|}{ Social } \\
\hline Normal & $36(100)$ & $18(100)$ \\
\hline Borderline & $0(0)$ & $0(0)$ \\
\hline Clinical & $0(0)$ & $0(0)$ \\
\hline \multicolumn{3}{|l|}{ Self-help } \\
\hline Normal & $36(100)$ & $18(100)$ \\
\hline Borderline & $0(0)$ & $0(0)$ \\
\hline Clinical & $0(0)$ & $0(0)$ \\
\hline \multicolumn{3}{|l|}{ Gross motor } \\
\hline Normal & $31(86.1)$ & I5 (83.3) \\
\hline Borderline & $5(13.9)$ & $3(16.7)$ \\
\hline Clinical & $0(0)$ & $0(0)$ \\
\hline \multicolumn{3}{|l|}{ Fine motor } \\
\hline Normal & 34 (94.4) & 17 (94.4) \\
\hline Borderline & $2(5.6)$ & I (5.6) \\
\hline Clinical & $0(0)$ & $0(0)$ \\
\hline \multicolumn{3}{|l|}{ Language } \\
\hline Normal & $36(100)$ & $18(100)$ \\
\hline Borderline & $0(0)$ & $0(0)$ \\
\hline Clinical & $0(0)$ & $0(0)$ \\
\hline \multicolumn{3}{|l|}{ Global } \\
\hline Normal & $36(100)$ & $18(100)$ \\
\hline Borderline & $0(0)$ & $0(0)$ \\
\hline Clinical & $0(0)$ & $0(0)$ \\
\hline
\end{tabular}

Notes: Data are presented as $\mathrm{n}$ (\%). Developmental quotients (that is, $\left.\left(\frac{\text { Developmental age }}{\text { Chronologicalage }}\right) \times 100\right)$ were classified as normal $(>85)$, borderline $(85-70)$, and clinical $(<70) .{ }^{26}$

children with borderline gross motor DQs (both 82.6) were the female twin pair identified with externalizing difficulties on the CBCL (children 1 and 2 in Table 3).

With respect to mean DQ scores (SD, range) across the cohort, these were as follows: social DQ $99.9(7.5,88-113)$, self-help DQ 102.1 (8.1, 89-126), gross motor DQ 96.2 (10.6, 71-119), fine motor DQ 97.7 (8.3, 84-120), language DQ $100.0(6.3,90-111)$, and overall DQ $99.2(6.5,86-113)$.

\section{Overall developmental concerns}

Taking into account the presence of overlap between results from the different screening methods, 11 cases were identified as meeting the criteria for developmental concerns on the questionnaire measures used. In addition, seven children were identified by parent report as having previously existing developmental or behavioral problems, namely speech delay requiring speech pathology $(\mathrm{n}=6)$, anxiety $(\mathrm{n}=2)$, and $\mathrm{CP}(\mathrm{n}=1)$. However, none of the children with previously indicated problems were identified in either the CBCL or the $\mathrm{CDC}$ tests. Thus, the overall rate of developmental concerns in this cohort was 18 of 44 children or $41 \%$ of the sample.
Detailed information regarding these 18 cases in relation to pregnancy-related factors is summarized in Table 3.

Statistical analyses were conducted to explore whether there were any significant relationships between the presence of developmental concerns and a number of the specific pregnancy/birth factors outlined in Table 3 . The comparison of pregnancy/birth factors between these groups is summarized in Table 6 . With alpha set at 0.05 , an independent $t$-test indicated that there was a difference that approached statistical significance between the developmental concerns and no developmental concerns groups with respect to birth weight $(t(42)=-1.9, P=0.06)$. There was a mean difference of $303 \mathrm{~g}$ between the developmental concerns cohort $(2,127 \mathrm{~g})$ and no developmental concerns cohort $(2,430 \mathrm{~g})$ which reflected a Cohen's $d$ effect size of 0.59 which is of medium size. Gestational age and birth weight were shown to be highly correlated (Pearson's $r(44)=0.76$ ), which is unsurprising given the well-understood relationship between the two variables. Interestingly, however, gestational age was not significantly different between the two groups $(t(42)=-1.5$, $P=0.13$, Cohen's $d=0.49$ ), which is approaching medium size. The relatively small size of the cohort prevented meaningful statistical comparison between the rates of assisted conception or the presence of birth weight discordance $>25 \%$. Results did, however, indicate that a higher proportion of the cohort with developmental concerns were conceived via assisted conception ( $17 \%$ vs $12 \%)$.

Similarly, males were overrepresented in the group with developmental concerns relative to those without such concerns $(61 \%$ vs $42 \%)$. Further, it was observed that there were a number of variables on the $\mathrm{CDC}$ where boys scored lower than girls overall, namely social DQ $(t(32)=-2.45, P=0.02$; boys mean $=96.8[5.9]$, girls mean $=102.7$ [7.8]), self-help DQ $(t(32)=-3.6, P<0.001$; boys mean $=97.6$ [5.1], girls mean $=106.2[8.2])$, fine motor DQ $(t(32)=-2.23, P=0.03$;

Table 6 Comparison of developmental data and pregnancy/birth factors

\begin{tabular}{|c|c|c|}
\hline $\begin{array}{l}\text { Pregnancy/birth } \\
\text { factor }\end{array}$ & $\begin{array}{l}\text { Developmental } \\
\text { concerns }(n=\mid 8)\end{array}$ & $\begin{array}{l}\text { No developmental } \\
\text { concerns }(n=26)\end{array}$ \\
\hline Assisted conception & $3(17 \%)$ & $3(12 \%)$ \\
\hline \multirow[t]{2}{*}{ Gestational age } & $246.3(11.1)$ & $252.8(3.0)$ \\
\hline & (35 weeks I day) & (36 weeks) \\
\hline Birth weight (g) & $2,127.4(537.6)$ & $2,404.82(525.2)$ \\
\hline $\begin{array}{l}\text { Presence of discordant } \\
\text { growth }>25 \%\end{array}$ & $2(11 \%)$ & $4(15 \%)$ \\
\hline Male child & II (6I\%) & II (42\%) \\
\hline
\end{tabular}

Note: Data are presented as $n(\%)$ or mean (SD).

Abbreviation: SD, standard deviation. 
boys mean $=94.6$ [5.9], girls mean $=100.6$ [9.2]), language DQ $(t(32)=-4.34, P<0.001$; boys mean $=96.0$ [4.8], girls mean $=103.6[5.3])$, and also the overall DQ $(t(32)=-3.43$, $P=0.002$; boys mean $=95.7$ [5.3], girls mean $=102.3$ [5.9]). There were no sex differences on gross motor DQ or on any aspects of the CBCL, however.

\section{Discussion}

Higher rates of neuromorbidity in twins are attributed mainly to prematurity, very low birth weight, and complications related to chorionicity. ${ }^{31}$ This cohort of 44 uncomplicated MCDA twins delivered with a mean gestational age of 35 weeks 5 days and a mean birth weight of 2,306 g, amongst the first such uncomplicated cohorts studied, reduces the influence of these factors. Consequently, it is expected that rates of complications would be low. The rate of $41 \%$ identified for developmental or behavioral concerns in this study is much higher than previous neuromorbidity estimates of $0.5 \%$ and $7 \%$ for similar cohorts; ${ }^{15,17}$ however, vast differences in sample sizes and negative outcome inclusion criteria as well as the use of different measures mean that comparisons are problematic. The present study has also included a range of markers of mild-to-moderate developmental concern.

The results of this study may be considered relative to population estimates of developmental delay, which refers to chronic conditions originating in childhood. ${ }^{32}$ A previous Australian research using the Parents Evaluation of Developmental Status ${ }^{33}$ has reported that $9 \%$ of children were classified as being at high risk of disabilities and 19\% were classified as being at medium risk. ${ }^{34}$ This is similar in international estimates and rates reported in other studies using other techniques, such as the $16.6 \%$ rate reported by Hamilton. ${ }^{35}$ Thus, neurodevelopmental and behavioral concerns in MCDA pregnancies would appear to occur at a rate higher, potentially around double, than that observed in the general population.

\section{Developmental difficulties}

The most prevalent developmental problem in this cohort was borderline motor delay, identified in seven of $36(19.4 \%)$ children with no other abnormal DQ scores. This finding is similar to that of Hack et al, ${ }^{14}$ who reported higher rates of locomotor difficulties, relative to other areas of development, in a cohort of MCDA twins assessed at 22 months of age using the Griffiths Mental Development Scales. In this regard, twinning has been suggested to be an independent risk factor for developmental delay with genetic factors contributing strongly to certain motor development outcomes. ${ }^{36}$ In a study of 84 pairs of mostly DC twins and 72 singletons from the Gambia, the mean age of achieving motor milestones, such as maintaining head stability, sitting without support, and walking, was found to be significantly higher in twins after adjustment for confounders, with over $90 \%$ of population variance attributed to genetic factors rather than environmental factors. ${ }^{36}$

Parent-reported language difficulties occurred within the cohort at a rate of $14 \%$. Hack et al ${ }^{14}$ also reported a slight increase in rates of language and hearing difficulties in $\mathrm{MC}$ relative to DC twins. More broadly, it is well documented that twins have more language difficulties than singletons, with the rationale for this placed not only on physiological differences. ${ }^{37}$ Twins are thought to be spoken to as an individual less frequently and for shorter periods of time by parents, given the temptation to address both together. ${ }^{38}$ A relationship has also been observed between the presence of a "secret language" between twins and language delay. ${ }^{39}$ Despite these twin-specific environmental and social influences, speech and language delay is common, with an estimated prevalence of $2.3 \%-29 \%$ in children aged $2-7$ years. More detailed understanding of the factors influencing on the development of language difficulties in this cohort is limited by the screening nature of the questionnaires used, although none of the children showed any indication of delay in the CDC.

Consistent with findings from the available literature regarding neurodevelopmental difficulties such as autism spectrum disorder and attention-deficit hyperactivity disorder, where males are affected at higher rates than females, several domain scores on the CDC were significantly lower amongst males than females, namely social DQ, self-help DQ, fine motor DQ, and language DQ. The overall DQ score was also significantly lower in boys, and males were overrepresented in the cohort of children in the study ultimately identified with developmental concerns, relative to those without such concerns (61\% vs $42 \%)$. These findings are reminiscent of twin data reported by Hack et al, ${ }^{14}$ and suggest that being male may confer an additional risk factor for neurodevelopmental difficulties.

Internalizing and externalizing problems are thought to affect up to $25 \%$ of youth in Australia. ${ }^{40}$ Current available estimates of high internalizing scores in normal singleton populations at age 5 suggest rates of $8 \%$ (borderline and clinical scores) and $4.6 \%$ (clinical scores only). ${ }^{40,41}$ A rate of $11.3 \%$ for CBCL-identified and parent report of diagnosed internalizing problems in the current cohort therefore 
does appear higher than would normally occur. It is difficult to determine the extent to which removal of extreme prematurity, low birth weight, and MC conditions from this cohort decreases the risk of developmental delay, given the small sample size of this study; however, it could be reasoned that for these behavioral problems, environmental factors may have played a role. For example, the relationship between parental anxiety and children's outcomes is well documented. ${ }^{42,43}$ While the collection of relatively limited personal data in this study means that environmental factors can only be speculated, a twin pregnancy, even when uncomplicated, and subsequent care of two infants can be considered a stressful event. ${ }^{38}$ Similarly, IVF conception may have added further to the stress of several of the parents in this cohort.

Clinical CBCL scores for externalizing problems were identified in three children, producing a rate of $6.8 \%$ in this cohort. Rates reported by Bayer et $\mathrm{al}^{40}$ and Potijk et $\mathrm{al}^{41}$ of $5.5 \%$ (borderline or clinical scores) and 5.2\% (clinical only), respectively, indicate that the present results are broadly consistent with population norms, if slightly higher; however, the influence of environmental factors on these rates would again require further investigation.

The above-noted modest developmental concerns regarding motor development, speech and language development, and socio-emotional development are amenable, in the main, to early intervention provided by allied professionals such as occupational therapists, speech pathologists, and psychologists. It would appear that one direct implication of this study would be for MCDA twins to have regular developmental checks with a pediatrician during the first several years of life so as to identify any emerging concerns quickly and obtain a referral for appropriate intervention. In Australia, there is a process for universal developmental surveillance, and parents could be explicitly encouraged and supported to adhere to attending regular developmental checks through until school-age, rather than dropping out as often occurs after the infant is aged around 12 months. ${ }^{44}$

One child presented with previously diagnosed CP, resulting in a prevalence of $2.3 \%$ within this population. Twins are known to have a four times greater rate of $\mathrm{CP}$ than singletons $(0.59 \%$ vs $0.14 \%)$, with a further increased risk of MCDA pregnancies. ${ }^{45}$ Studies by Ortibus et $\mathrm{al}^{17}$ and Hack et $\mathrm{al}^{14}$ have reported rates of $2 \%$ and $2.2 \%$, respectively, in complicated MCDA cohorts; however, Ortibus et $\mathrm{al}^{17}$ reported a $\mathrm{CP}$ rate in uncomplicated MCDA twins of only $0.63 \%$, which is more comparable with overall twin estimates. A number of risk factors can increase the likelihood of $\mathrm{CP}$ in twins, including discordant growth and preterm birth, with $20 \%$ of CP cases in twins occurring in children born between 32 and 36 weeks of gestation. ${ }^{46}$ The child with $\mathrm{CP}$ in the current sample had a gestational age of 35 weeks 2 days and a high birth weight discordancy of $22.5 \%$. Assisted reproductive technology (ART) is also considered to increase the likelihood of CP; however, this is likely to be attributable to higher rates of twinning and resultant complications, such as prematurity. ${ }^{46}$ ART was found to be responsible for higher rates of neuromorbidity in MCDA twins; ${ }^{17}$ however, these findings were based on a cohort of both complicated and uncomplicated cases, making comparison with the current sample difficult.

\section{Pregnancy/birth factors}

Birth weight and gestational age were the only pregnancy/ birth factors able to be analyzed for statistical significance in this study. The developmental concerns group tended to have a lower birth weight $(P=0.06)$ of medium effect size. Gestational age was not significantly different between the groups; however, the correlation between birth weight and gestational age was high at $r=0.76$. This expected finding adds additional validity to the measures used in the study to determine neurodevelopmental and behavioral concerns, and when considered alongside evidence from the literature regarding the timing of delivery, ${ }^{47}$ this also appears to further support the argument for later delivery. ${ }^{48}$

While the majority of extant research has focused on outcomes of MCDA pregnancies with abnormal clinical episodes, these cases may be considered the more extreme end of a spectrum that extends from MCDA twins with no anastomoses and equal share, to various imbalances of blood volume distribution associated with the different types of anastomoses for varying periods of time. For example, it is widely accepted that during a pregnancy with no intervention for TTTS or sIUGR, one may see significant amniotic fluid discordance commonly which usually resolves. ${ }^{49}$ Furthermore, in uncomplicated MCDA twins managed with scan surveillance every 2 weeks who have reached the third trimester of pregnancy, unexpected fetal loss risk as high as $4.3 \%$ at 32 weeks of gestation has been reported, ${ }^{18}$ or a comparable magnitude $(3.8 \%)$ of pregnancies with infants having severe neurodevelopmental delay following the prenatal diagnosis of unexpected acute-onset complications. ${ }^{50}$ This demonstrates that MCDA fetal development is exposed to significantly greater changes in physiology than DC twins, which in turn may negatively influence neurodevelopmental outcomes. The mechanisms underlying this require further 
research including MCDA cases nominally described as uncomplicated.

\section{Limitations and further research}

As well as small cohort size, aspects of the methodology may have influenced the outcomes of this study. The questionnaires used to obtain data in this study were parent-completed screening tests, as opposed to the direct pediatric developmental evaluations as used in several available studies. ${ }^{14,15,17}$ Nonetheless, parent report of child development using structured tools is thought to be accurate relative to observational measures, ${ }^{27-29}$ and many aspects of the present results, including lower developmental scores across many domains for boys, and relatively high rates of motor difficulties, are consistent with the findings of Hack et al, ${ }^{14}$ who used the Griffiths Mental Development Scales. Furthermore, in that study, parent report using the HSCS-PS was also found to be commensurate with the Griffiths results. Screening tests are designed to identify groups at sufficient risk to warrant a more in-depth evaluation, rather than providing a quantitative assessment or diagnosis and therefore potentially have a higher rate of positive results. ${ }^{51}$ Furthermore, it has been suggested that this problem is more pronounced for twins, where parents must remember two separate developmental trajectories and are likely to compare and contrast the two children, potentially leading to an overestimation or underestimation of differences between the two. ${ }^{52}$ In any event, the observed differences between parent-structured questionnaire report of difficulties (eg, CDC, CBCL) and parent qualitative report of previously diagnosed difficulties merit investigation in future studies.

Data were initially extracted from the FMU by selecting for MC status and then further condensing the cohort manually based on date of birth and gestational age; however, more detailed cross-referencing with hospital databases revealed that a number of patients included did not truly fit the MCDA inclusion criteria. A total of 27 of 90 patients were revealed as inappropriate, meaning that patients were correctly identified at a rate of $70 \%$. While these cases did not affect the final outcome of this study, they do cast doubt on the specificity and reproducibility of the method. The size, timing, and differences in Liverpool FMU protocol for the screening and care of DC twins also meant that comparison with DC data from within the same selection population was not possible. Comparison with a control would have better contextualized the results, and the contrast between the two groups may have highlighted trends not as obvious in this study.
One of the elements of this study that we would like to have further explored is the specific details of chorionicity. Problems with determining chorionicity sonographically would most likely not have affected our results; however, more detailed analysis of placental histology may have highlighted relationships unable to be tested in this study. Placental angioarchitecture in relation to clinical outcome is an interesting and fast-developing area of research, and while the size and resources of this study did not allow for further investigation, it is an area that will hopefully be researched by this facility in the future. In any event, longerterm follow-up studies would appear to be strongly indicated with MCDA cohorts.

\section{Conclusion}

Within this cohort of preschool-aged MCDA twins, we observed a high rate of neurodevelopmental concerns (41\%) of mild-to-moderate severity. While these encompassed a wide range of concerns, lower average scores for motor (19\%) and speech and language (14\%) development, as well as internalizing difficulties (11\%) predominated. Consistent with the existing literature, the presence of developmental concerns was associated with a lower birth weight. However, further studies are needed to elucidate whether twinning in itself may increase the risk for developmental delay, and in particular motor development, and the unique contributions of genetic factors including on placental development in addition to perinatal factors such as low birth weight and prematurity. Further research with an increased sample size and a refined methodology are required to understand the possible mechanisms and to give more clinical significance to these conclusions.

\section{Acknowledgments}

The study was completed as part of the Independent Learning Project of author A Sierakowski, with some assistance by Deborah Lim, within the medical degree curriculum through the School of Medicine, University of New South Wales. The authors would like to thank Ben Chifley for his statistical advice, and parents from and the staff of the Department of Maternal-Fetal Medicine at Liverpool Hospital who kindly gave their time to participate.

\section{Disclosure}

The authors report no conflicts of interest in this work.

\section{References}

1. Corsello G, Piro E. The world of twins: an update. J Matern Fetal Neonatal Med. 2010;23 (Suppl 3):59-62. 
2. Bajoria R, Kingdom J. The case for routine determination of chorionicity and zygosity in multiple pregnancy. Prenat Diagn. 1997;17(13): 1207-1225.

3. Sperling L, Kiil C, Larsen LU, et al. Naturally conceived twins with monochorionic placentation have the highest risk of fetal loss. Ultrasound Obstet Gynecol. 2006;28(5):644-652.

4. Trop I. The twin peak sign. Radiology. 2001;220(1):68-69.

5. Wood SL, St Onge R, Connors G, Elliot PD. Evaluation of the twin peak or lambda sign in determining chorionicity in multiple pregnancy. Obstet Gynecol. 1996;88(1):6-9.

6. Acosta-Rojas R, Becker J, Munoz-Abellana B, Ruiz C, Carreras E, Gratacos E; Catalunya and Balears Monochorionic Network. Twin chorionicity and the risk of adverse perinatal outcome. Int J Gynecol Obstet. 2007;96(2):98-102.

7. Ohm Kyvik K, Derom C. Data collection on multiple births - establishing twin registers and determining zygosity. Early Hum Dev. 2006;82(6):357-363.

8. Sebire NJ, Snijders RJ, Hughes K, Sepulveda W, Nicolaides KH. The hidden mortality of monochorionic twin pregnancies. Br J Obstet Gynaecol. 1997;104(10):1203-1207.

9. Hack KE, Derks JB, Elias SG, et al. Increased perinatal mortality and morbidity in monochorionic versus dichorionic twin pregnancies: clinical implications of a large Dutch cohort study. BJOG. 2008;115(1):58-67.

10. Lewi L, Deprest J, Hecher K. The vascular anastomoses in monochorionic twin pregnancies and their clinical consequences. Am J Obstet Gynecol. 2013;208(1):19-30.

11. Hillman SC, Morris RK, Kilby MD. Co-twin prognosis after single fetal death: a systematic review and meta-analysis. Obstet Gynecol. 2011;118(4):928-940.

12. Rossi AC, Vanderbilt D, Chmait RH. Neurodevelopmental outcomes after laser therapy for twin-twin transfusion syndrome: a systematic review and meta-analysis. Obstet Gynecol. 2011;118(5):1145-1150.

13. Ong SS, Zamora J, Khan KS, Kilby MD. Prognosis for the co-twin following single-twin death: a systematic review. BJOG. 2006;113(9): 992-998.

14. Hack KE, Koopman-Esseboom C, Derks JB, et al. Long-term neurodevelopmental outcome of monochorionic and matched dichorionic twins. PLoS One. 2009;4(8):e6815.

15. Adegbite AL, Castille S, Ward S, Bajoria R. Neuromorbidity in preterm twins in relation to chorionicity and discordant birth weight. Am JObstet Gynecol. 2004;190(1):156-163.

16. Minakami H, Honma Y, Matsubara S, Uchida A, Shiraishi H, Sato I Effects of placental chorionicity on outcome in twin pregnancies. A cohort study. J Reprod Med. 1999;44(7):595-600.

17. Ortibus E, Lopriore E, Deprest J, et al. The pregnancy and long-term neurodevelopmental outcome of monochorionic diamniotic twin gestations: a multicenter prospective cohort study from the first trimester onward. Am J Obstet Gynecol. 2009;200(5):494.e1-494.e8.

18. Barigye O, Pasquini L, Galea P, Chambers H, Chappell L, Fisk NM. High risk of unexpected late fetal death in monochorionic twins despite intensive ultrasound surveillance: a cohort study. PLoS Med. 2005;2(6):e172.

19. South Western Sydney Local Health District. Liverpool health profile. 2010. Available from: http://www.swslhd.nsw.gov.au/planning/. Accessed December 18, 2016.

20. De Groot R, Van Den Wijngaard JP, Umur A, Beek JF, Nikkels PG, Van Gemert MJ. Modeling acardiac twin pregnancies. Ann N Y Acad Sci. 2007;1101:235-249.

21. Quintero RA, Morales WJ, Allen MH, Bornick PW, Johnson PK, Kruger M. Staging of twin-twin transfusion syndrome. J Perinatol. 1999; 19(8 Pt 1):550-555.

22. van Gemert MJ, Umur A, Tijssen JG, Ross MG. Twin-twin transfusion syndrome: etiology, severity and rational management. Curr Opin Obstet Gynecol. 2001;13(2):193-206.

23. Achenbach TM, Rescorla LA. Child Behaviour Checklist for Ages 1.5-5. Burlington, VT: Research Center for Children, Youth, \& Families, University of Vermont; 1998.
24. Ireton HR, Vader H. Child Development Review: Instructions Manual. Minneapolis, MN: Behavior Science Systems, Inc.; 2004.

25. Achenbach TM. CBCL/2-3 Profile for Boys and Girls. Burlington, VT: Department of Psychiatry, University of Vermont; 1992.

26. Johnson CP, Blasco PA. Infant growth and development. Pediatr Rev. 1997; 18(7):224-242.

27. Glascoe FP, Dworkin PH. The role of parents in the detection of developmental and behavioral problems. Pediatrics. 1995;95(6):829-836.

28. Squires J, Bricker D, Potter L. Revision of a parent-completed development screening tool: Ages and Stages Questionnaires. J Pediatr Psychol. 1997;22(3):313-328.

29. Bedford H, Walton S, Ahn J. Measures of Child Development: A Review. London: Centre for Paediatric Epidemiology and Biostatistics, UCL Institute of Child Health: Policy Research Unit in the Health of Children, Young People and Families; 2013.

30. Campbell DM, MacGillivray I. Preeclampsia in twin pregnancies: incidence and outcome. Hypertens Pregnancy. 1999;18(3):197-207.

31. Pharoah P. Neurological outcome in twins. Semin Neonatol. 2002;7(3): 223-230.

32. Boyle CA, Decouflé P, Yeargin-Allsopp M. Prevalence and health impact of developmental disabilities in US children. Pediatrics. 1994;93(3):399-403.

33. Glascoe FP. Parents' Evaluations of Developmental Status: A Method for Detecting and Addressing Developmental and Behavioral Problems in Children. Nashville, TN: Ellsworth \& Vandermeer Press; 2006.

34. Coghlan D, Kiing JS, Wake M. Parents' evaluation of developmental status in the Australian day-care setting: developmental concerns of parents and carers. J Paediatr Child Health. 2003;39(1):49-54.

35. Hamilton S. Screening for developmental delay: reliable, easy-to-use tools. J Fam Pract. 2006;55(5):415-422.

36. Goetghebuer T, Ota MO, Kebbeh B, et al. Delay in motor development of twins in Africa: a prospective cohort study. Twin Res. 2003;6(4):279-284.

37. Rutter M, Thorpe K, Greenwood R, Northstone K, Golding J. Twins as a natural experiment to study the causes of mild language delay: I: design; twin-singleton differences in language, and obstetric risks. J Child Psychol Psychiatry. 2003;44(3):326-341.

38. Rutter M, Redshaw J. Annotation: growing up as a twin: twin-singleton differences in psychological development. J Child Psychol Psychiatry. 1991;32(6):885-895.

39. Thorpe K, Greenwood R, Eivers A, Rutter M. Prevalence and developmental course of 'secret language'. Int J Lang Commun Disord. 2001;36(1):43-62.

40. Bayer JK, Ukoumunne OC, Mathers M, Wake M, Abdi N, Hiscock H. Development of children's internalising and externalising problems from infancy to five years of age. Aust N Z J Psychiatry. 2012;46(7):659-668.

41. Potijk MR, de Winter AF, Bos AF, Kerstjens JM, Reijneveld SA. Higher rates of behavioural and emotional problems at preschool age in children born moderately preterm. Arch Dis Child. 2012;97(2):112-117.

42. Kovacs M, Devlin B. Internalizing disorders in childhood. J Child Psychol Psychiatry. 1998;39(1):47-63.

43. Weissman MM, Leckman JF, Merikangas KR, Gammon GD, Prusoff BA. Depression and anxiety disorders in parents and children. Results from the Yale family study. Arch Gen Psychiatry. 1984;41(9): $845-852$.

44. Eapen V, Woolfenden S, Williams K, et al. "Are you available for the next 18 months?" - methods and aims of a longitudinal birth cohort study investigating a universal developmental surveillance program: the 'Watch Me Grow' study. BMC Pediatr. 2014;14:234.

45. Scher AI, Petterson B, Blair E, et al. The risk of mortality or cerebral palsy in twins: a collaborative population-based study. Pediatr Res. 2002;52(5):671-681.

46. Saunders NR, Hellmann J, Farine D. Cerebral palsy and assisted conception. J Obstet Gynaecol Can. 2011;33(10):1038-1043.

47. Sullivan AE, Hopkins PN, Weng HY, et al. Delivery of monochorionic twins in the absence of complications: analysis of neonatal outcomes and costs. Am J Obstet Gynecol. 2012;206(3):257.e1-257.e7. 
48. Morris JM, Roberts CL, Bowen JR, et al; PPROMT Collaboration. Immediate delivery compared with expectant management after preterm pre-labour rupture of the membranes close to term (PPROMT trial): a randomised controlled trial. Lancet. 2016;387(10017):444-452.

49. O’Donoghue K, Cartwright E, Galea P, Fisk NM. Stage I twin-twin transfusion syndrome: rates of progression and regression in relation to outcome. Ultrasound Obstet Gynecol. 2007;30(7):958-964.

50. Smoleniec J. MCDA twin ultrasound surveillance and complications after 28 weeks. In: Proceedings of the TTTS Eurofetus Conference; May 1-8, 2008; Leuven, Belgium.
51. Voigt RG, Llorente AM, Jensen CL, Fraley JK, Barbaresi WJ, Heird WC. Comparison of the validity of direct pediatric developmental evaluation versus developmental screening by parent report. Clin Pediatr (Phila). 2007;46(6):523-529.

52. Langendonk JM, van Beijsterveldt CE, Brouwer SI, Stroet T, Hudziak JJ, Boomsma DI. Assessment of motor milestones in twins. Twin Res Hum Genet. 2007;10(6):835-839.

\section{Publish your work in this journal}

Neuropsychiatric Disease and Treatment is an international, peerreviewed journal of clinical therapeutics and pharmacology focusing on concise rapid reporting of clinical or pre-clinical studies on a range of neuropsychiatric and neurological disorders. This journal is indexed on PubMed Central, the 'PsycINFO' database and CAS, and is the official journal of The International Neuropsychiatric Association (INA). The manuscript management system is completely online and includes a very quick and fair peer-review system, which is all easy to use. Visit http://www.dovepress.com/testimonials.php to read real quotes from published authors.

Submit your manuscript here: http://www.dovepress.com/neuropsychiatric-disease-and-treatment-journal 